\title{
Correction to: Comprehensive geriatric assessment and decision-making in older men with incurable but manageable (chronic) cancer
}

\author{
Catherine Handforth ${ }^{1,2} \cdot$ Roger Burkinshaw ${ }^{1} \cdot$ Jenny Freeman ${ }^{1} \cdot$ Janet E. Brown ${ }^{1,2} \cdot$ John A. Snowden ${ }^{1,3}$. \\ J. Fearnside ${ }^{1} \cdot$ Robert E. Coleman $^{1,2}$ - Diana M. Greenfield ${ }^{1,2}$ \\ Published online: 20 November 2020 \\ (C) Springer-Verlag GmbH Germany, part of Springer Nature 2020
}

\section{Supportive Care in Cancer (2019) 27:1755-1763}

https://doi.org/10.1007/s00520-018-4410-z

The original version of this paper unfortunately contained an error. The name of Jane Fearnside was omitted and is now corrected in the author group of this article.

The citation should read: Handforth C, Burkinshaw R, Freeman J, Brown JE, Snowden JA, Fearnside J, Coleman RE, Greenfield D. Comprehensive geriatric assessment and decision-making in older men with incurable but manageable (chronic) cancer.

Publisher's note Springer Nature remains neutral with regard to jurisdictional claims in published maps and institutional affiliations.

The online version of the original article can be found at https://oi.org/ $10.1007 / \mathrm{s} 00520-018-4410-\mathrm{z}$

Catherine Handforth

C.Handforth@sheffield.ac.uk

Diana M. Greenfield

diana.greenfield@nhs.net

1 University of Sheffield, Sheffield, UK

2 Weston Park Hospital, Sheffield Teaching Hospitals NHS Foundation Trust, Whitham Road, Sheffield S10 2SJ, UK

3 Royal Hallamshire Hospital, Sheffield Teaching Hospitals NHS Foundation Trust, Glossop Rd, Sheffield S10 2JF, UK 